\title{
Endoscopic Management of Upper Urinary Tract Urothelial Carcinoma
}

\author{
Bong Hee Park, Seong Soo Jeon ${ }^{1}$ \\ Department of Urology, Incheon St. Mary's Hospital, The Catholic University of Korea College of Medicine, Incheon, ${ }^{1}$ Department of Urology, \\ Samsung Medical Center, Sungkyunkwan University School of Medicine, Seoul, Korea
}

\begin{abstract}
Upper urinary tract urothelial carcinoma (UTUC) is relatively uncommon. Radical nephroureterectomy with an ipsilateral bladder cuff excision has been the gold standard treatment for UTUC. However, recent advances in technology have made possible the increased use of endoscopic management for the treatment of UTUC. The definitive goal of endoscopic management of UTUC is cancer control while maintaining renal function and the integrity of the urinary tract. Endoscopic management includes both the retrograde ureteroscopic and antegrade percutaneous approaches. The endoscopic management of UTUC is a reasonable alternative for patients with renal insufficiency or a solitary functional kidney, bilateral disease, or a significant comorbidity that precludes radical surgery. Select patients with a functional contralateral kidney who have low-grade, low-stage tumors may also be candidates for endoscopic management. The careful selection of patients is the most important point for the successful endoscopic management of UTUC. It is crucial that patients are compliant and motivated, because a lifetime protocol of strict surveillance is necessary. Adjuvant topical therapy with Bacillus Calmette-Guerin or mitomycin $\mathrm{C}$ can be used after endoscopic management of UTUC in an attempt to reduce recurrence. In this article, we review current endoscopic techniques, indications for endoscopic treatment, clinical outcomes of endoscopic management, adjuvant topical therapy, and surveillance in patients with UTUC.
\end{abstract}

\section{Keywords: Adjuvant treatment; Endoscopy; Percutaneous resection; Transitional cell carcinoma; Ureteroscopy}

This is an Open Access article distributed under the terms of the Creative Commons Attribution Non-Commercial License (http://creativecommons.org/licenses/by-nc/3.0) which permits unrestricted non-commercial use, distribution, and reproduction in any medium, provided the original work is properly cited.

\author{
Article History: \\ received 10 May, 2013 \\ accepted 27 May, 2013
}

Corresponding Author:

Seong Soo Jeon

Department of Urology, Samsung Medical Center, Sungkyunkwan University School of Medicine, 81 Irwon-ro, Gangnam-gu, Seoul 135-710, Korea

TEL: +82-2-3410-3555

FAX: +82-2-3410-6992

E-mail: seongsoo.jeon@samsung. com

\section{INTRODUCTION}

Upper urinary tract urothelial carcinoma (UTUC) is uncommon, accounting for only $5 \%$ to $6 \%$ of all urothelial carcinomas [1]. The estimated annual incidence in Western countries is about 2 new cases per 100,000 individuals [2]. The peak incidence of UTUC is in the seventh and eighth decades of life, and UTUC occurs three times more frequently in men than in women [3]. Whereas just $15 \%$ to $25 \%$ of bladder tumors are invasive at diagnosis, $60 \%$ of UTUCs are invasive at diagnosis [4] and UTUCs have a poorer prognosis. Radical nephroureterectomy (RNU) with excision of the ipsilateral bladder cuff is considered to be the gold standard treatment for UTUC [5].
However, despite radical surgical intervention, it has become increasingly recognized that a significant proportion of patients still die from their disease, possibly as a result of micrometastasis at the time of operation, with a 5 -year disease-specific mortality of $15 \%$ to $30 \%$ [6]. Thus, endoscopic management of UTUC has gained interest. Several facets of endoscopic management, including the potential benefits of nephron-sparing surgery, the multifocal recurrent nature of UTUC, and the evolution in endoscopic technology, have contributed to this interest.

The recently published 2013 European Association of Urology Guidelines indicate that conservative management of UTUC can be considered in imperative or elective cases for low-grade, low-stage tumors [2]. In this article, we 
review the current literature with regard to the endoscopic management of UTUCs.

\section{ENDOSCOPIC MANAGEMENT}

Advances in endoscopic technology, including the development of improved optics, progressively smaller and more durable rigid and flexible endoscopes, actively deflecting telescopes, and adjunctive instrumentation, have enabled endoscopic management to become more practical and efficacious when used for both diagnostic and therapeutic purposes in UTUC cases [7]. Traditionally, endoscopic management of UTUC was recommended only for patients with imperative indications, such as renal insufficiency or a solitary functional kidney, bilateral disease, or a significant comorbidity that precluded radical surgery. Recently, however, the 2013 European Association of Urology Guidelines suggested that endoscopic management of UTUC could also be used for elective cases (when the contralateral kidney is functional) if specific criteria are met, such as a unifocal tumor, tumor size $<1 \mathrm{~cm}$, low-grade tumor (cytology or biopsies), no evidence of an infiltrative lesion on computed tomography (CT) urography, and an understanding of the necessity of close follow-up [2].

Direct visualization of upper urinary tract tumors can be obtained by using tumor biopsy specimens and selective urine cytology. Tumor grading in this setting is very accurate and is $90 \%$ in agreement with the grade of the final histopathological specimen [7]. Although ureteroscopy has not been demonstrated to be a dependable method of staging and therefore has been characterized by some authors as unreliable in determining stage [8], recent reports suggest a highly reliable concordance between biopsy grade and histopathological stage [9]. In addition, CT urography can detect with high accuracy evidence of UTUC extending beyond the wall of the ureter or renal pelvis [10]. Therefore, more accurate UTUC characterization can be obtained through the combination of tumor grading on biopsy and clinical staging by CT urography. Endoscopic management of UTUC can be performed via either an ureteroscopic retrograde or a percutaneous antegrade approach.

\section{URETEROSCOPIC MANAGEMENT}

Advances in ureteroscopic techniques and instruments allow for retrograde access to the entire upper urinary tract. Small-diameter rigid and flexible ureteroscopes with greater deflecting abilities have been combined with endoscopic biopsy techniques and devices for tissue ablation to offer practical approaches to managing upper urinary tract tumors [11]. The principal advantage of retrograde endoscopy is its low morbidity while maintaining urothelial integrity [12]. However, the ureteroscopic approach is limited by the size of the instruments that can be adjusted in the ureter and the size of tumor that can be adequately managed. Some parts of the upper urinary tract, such as the lower calyces, are less accessible when using the retro- grade approach. Also, the retrograde ureteroscopic approach is difficult in patients who have undergone a previous urinary diversion.

Following retrograde access, a UTUC of the distal ureter is cleared with a rigid ureteroscope, and the remains of the ureter and renal pelvis are observed with a flexible ureteroscope. After an initial biopsy of the lesion, available management options are performed and can include mechanical debulking (cold-cup forceps or stone basket), electrofulguration, electroresection, laser photo-coagulation, or ablation. Mechanical removal of small UTUCs can be very effective, and the biopsy process can remove significant volumes of tumor. An electrosurgical technique was first used for the management of ureteral tumors, but the use of this technique is mostly confined to the distal ureter owing to the rigid design of the resectoscope.

In particular, the holmium:yttrium aluminum garnet (Ho:YAG) and neodymium:yttrium aluminum garnet (Nd:YAG) lasers used to cauterize and ablate UTUCs, which are supplied through small-diameter, flexible fibers, permit the management of relatively large UTUCs. The Ho:YAG laser is effective because it can both coagulate and ablate tissue and has minimal tissue penetration $(<0.5$ $\mathrm{mm}$ ) and therefore can be used for ureteric lesions [7]. The $\mathrm{Nd}$ :YAG laser has been used widely for the treatment of both bladder and upper tract tumors. It has a greater depth of penetration (4-6 $\mathrm{mm}$ ) and provides a deeper coagulation and ablative effect on the tumor [13]. The two lasers can be used in combination. The Nd:YAG laser, penetrating to a depth of several millimeters, is used to coagulate the major volume of the tumor, and then the coagulated tissue can be removed with the Ho:YAG laser [14].

Treatment outcomes from the current literature of ureteroscopic management for UTUC are summarized in Table 1. Upper urinary tract and bladder recurrence rates for patients managed ureteroscopically are reported to be $20 \%$ to $90 \%$ and $15 \%$ to $53 \%$, respectively, and several studies with limited follow-up have suggested $45 \%$ to $100 \%$ overall survival (OS) and $82 \%$ to $100 \%$ cancer-specific survival (CSS). Cutress et al. [6] recently reviewed the oncologic outcomes of 73 patients undergoing ureteroscopic management of UTUC. Upper urinary recurrence occurred in $68 \%$ (50/73), and $19 \%$ of the patients (14/73) eventually proceeded to nephroureterectomy. The estimated OS and CSS were $69.7 \%$ and $88.9 \%$, respectively, at 5 years, and $40.3 \%$ and $77.4 \%$, respectively, at 10 years. The estimated mean and median OS times were 119 months and 107 months, respectively. The median follow-up was 54 months. Similar results were reported by Cornu et al. [15] in 35 patients undergoing ureteroscopic resection of UTUC. The 3-year cancer-specific and recurrence-free survival rates were $100 \%$ and $35 \%$, respectively. The median interval to recurrence was 10 months, and four patients ultimately underwent nephroureterectomy.

The foremost complications associated with ureteroscopic management are postoperative stricture and ureteral perforation. Complication rates have decreased with de- 
TABLE 1. Outcomes of series using ureteroscopic management for UTUC

\begin{tabular}{lcllcrrrr}
\hline \multicolumn{1}{c}{ Series } & $\begin{array}{c}\text { No. of } \\
\text { patients }\end{array}$ & $\begin{array}{c}\text { Bx (G1/G2/G3) } \\
(\mathrm{n})\end{array}$ & $\begin{array}{c}\text { Follow-up } \\
(\mathrm{mo})\end{array}$ & $\begin{array}{c}\text { UT Rec } \\
(\%)\end{array}$ & $\begin{array}{c}\text { BL Rec } \\
(\%)\end{array}$ & $\begin{array}{c}\text { OS } \\
(\%)\end{array}$ & $\begin{array}{c}\text { CSS } \\
(\%)\end{array}$ & $\begin{array}{c}\text { NUx } \\
(\%)\end{array}$ \\
\hline Fajkovic et al. [32] & 20 & 17(LG14/HG3) & Mean, 20 & 25 & 15 & 45 & 95 & 0 \\
Cutress et al. [6] & 73 & $59(34 / 19 / 6)$ & Median, 54 & 68 & 53 & 60 & 90 & 19 \\
Cornu et al. [15] & 35 & $22($ LG16/HG6) & Mean, 24 & 60 & 40 & 100 & 100 & 11 \\
Pak et al. [33] & 57 & NR & Mean, 53 & 90 & NR & 93 & 95 & 19 \\
Lucas et al. [34] & 39 & $39($ LG27/HG12) & Median, 33 & 46 & NR & 62 & 82 & 28 \\
Johnson et al. [35] & 35 & $35(35 / 0 / 0)$ & Mean, 32 & 68 & NR & NR & 100 & 3 \\
Deligne et al. [36] & 61 & $53(21 / 24 / 8)$ & Mean, 40 & 25 & 23 & 76 & 85 & 18 \\
Keeley et al. [37] & 41 & $40(21 / 14 / 5)$ & Median, 26 & 20 & 37 & NR & 100 & 20 \\
\hline
\end{tabular}

UTUC, upper urinary tract urothelial carcinoma; Bx, biopsy; FU, follow-up; UT Rec, upper urinary tract recurrence; BL Rec, bladder recurrence; OS, overall survival; CSS, cancer-specific survival; NUx, patients proceeding to nephroureterectomy; LG, low grade; HG, high grade; NR, not reported.

velopments in instrumentation and technique. The incidence of perforation is $0 \%$ to $10 \%$, and perforations are treated by ureteral stenting or percutaneous nephrostomy drainage [7]. The stricture rate ranges from $5 \%$ to $14 \%$ [16]. Evidence suggests that a lower incidence of stricture is associated with lesions treated by laser ablation rather than by electrocoagulation [12]. Most strictures can be treated by ureteral stenting, laser incision, or balloon dilation [17]. Generally, ureteroscopic management has a notably lower requirement for blood transfusion and a lower overall complication rate than does percutaneous management [18].

Proper patient selection is crucial when considering primary ureteroscopic treatment of UTUC. Painter et al. [19] classified 45 patients who underwent ureteroscopic treatment of UTUC into elective, relative (patients who rejected radical surgery), and imperative groups. At 24 months of follow-up, the CSS was 100\% in the elective group. In comparison, 12 of 16 patients in the relative group required nephroureterectomy, and 6 patients had stage pT2 or greater disease on the final histopathological examination. Thus, ureteroscopic management should be considered for low-volume, low-grade UTUC in healthy populations who are candidates for radical treatment. Boorjian et al. [20] compared 121 patients who underwent nephroureterectomy, 75 patients who underwent nephroureterectomy after ureteroscopic biopsy, and 12 patients who underwent tumor ablation. No significant difference was found in CSS among the three groups $(85 \%, 81 \%$, and $83 \%$, respectively) at a mean follow-up of 37 months. An important point is that ureteroscopic biopsy or ablation before radical surgery does not adversely affect the oncologic outcomes compared with immediate radical nephron-ureterectomy.

\section{PERCUTANEOUS MANAGEMENT}

Although the ureteroscopic retrograde approach has the benefit of conserving a closed urinary system, the percutaneous antegrade approach can be considered for low-grade or noninvasive UTUC in the renal cavities [2]. The principal advantage of the percutaneous approach is that it al- lows for the removal of a larger tumor volume from any site of the collecting system owing to the use of instruments with larger working channels, which allows better visualization and faster resection [7]. The percutaneous approach also allows better access to the lower caliceal system, which is inaccessible by flexible ureteroscopy.

After the establishment of a percutaneous tract, the lesion is initially biopsied and subsequently debulked. Various techniques have been used for tumor ablation, including monopolar and bipolar electrocautery, rollerball electrodes, lasers, and electrovaporization [21]. The whole tumor is ablated, and the base of the lesion is resected or fulgurated. The base of the UTUC is separately resected and sent for staging. Hemostasis is achieved by laser ablation or electrocautery. The established nephrostomy tract can be maintained, allowing for repeated treatment or administration of topical adjuvant therapy [14].

Treatment outcomes in the current literature for the percutaneous management of UTUC are summarized in Table 2. Upper urinary tract and bladder recurrence rates for patients managed percutaneously are reported to be $13 \%$ to $65 \%$ and $15 \%$ to $42 \%$, respectively, and several studies with limited follow-up suggested OS of $68 \%$ to $96 \%$ and CSS of $75 \%$ to $100 \%$. Palou et al. [22] retrospectively reviewed 34 patients who underwent percutaneous management of UTUC; $15 \%$ had grade 3 tumors with either a solitary kidney or bilateral disease. During 51 months of follow-up, upper urinary tract recurrence was found in $44 \%$ of cases, at a median time of 24 months. Nine patients required nephroureterectomy. Kidney preservation was achieved in $74 \%$ of cases. The rates of OS and CSS were $74 \%$ and $94 \%$, respectively.

In a more recent study, Roupret et al. [23] reported on the outcomes of 24 patients who underwent a percutaneous approach for UTUC. During follow-up, which was a median of 62 months, eight recurrences were detected at a median time of 17 months. Three recurrences were in the ipsilateral ureter, one in the contralateral ureter, and four in the bladder. Five patients with high-grade or invasive tumors subsequently required nephroureterectomy; one pa- 
TABLE 2. Outcomes of series using percutaneous management for UTUC

\begin{tabular}{|c|c|c|c|c|c|c|c|c|}
\hline Series & $\begin{array}{c}\text { No. of } \\
\text { patients }\end{array}$ & $\begin{array}{c}\mathrm{Bx}(\mathrm{G} 1 / \mathrm{G} 2 / \mathrm{G} 3) \\
\text { (n) }\end{array}$ & $\begin{array}{l}\text { Follow-up } \\
\text { (mo) }\end{array}$ & $\begin{array}{l}\text { UT Rec } \\
(\%)\end{array}$ & $\begin{array}{c}\text { BL Rec } \\
(\%)\end{array}$ & $\begin{array}{l}\text { OS } \\
(\%)\end{array}$ & $\begin{array}{l}\text { CSS } \\
(\%)\end{array}$ & $\begin{array}{c}\mathrm{NUx} \\
(\%)\end{array}$ \\
\hline Rastinehad et al. [25] & 89 & 89 (LG50/HG39) & Mean, 61 & 33 & NR & 68 & NR & 13 \\
\hline Roupret et al. [23] & 24 & 24 (LG17/HG7) & Median, 62 & 13 & 17 & 79 & 83 & 21 \\
\hline Palou et al. [22] & 34 & $33(7 / 21 / 5)$ & Mean, 51 & 44 & NR & 74 & 94 & 26 \\
\hline Goel et al. [38] & 20 & 20 (LG15/HG5) & Mean, 64 & 65 & 15 & NR & 75 & 50 \\
\hline Clark et al. [39] & 18 & $18(6 / 8 / 4)$ & Mean, 24 & 33 & NR & 75 & 82 & 12 \\
\hline Patel et al. [40] & 26 & $23(11 / 11 / 1)$ & Mean, 45 & 35 & 42 & 75 & 91 & 6 \\
\hline Fuglsig and Krarup [41] & 26 & $\mathrm{NR}$ & Mean, 21 & 31 & NR & 96 & 100 & 35 \\
\hline
\end{tabular}

UTUC, upper urinary tract urothelial carcinoma; Bx, biopsy; FU, follow-up; UT Rec, upper urinary tract recurrence; BL Rec, bladder recurrence; OS, overall survival; CSS, cancer-specific survival; NUx, patients proceeding to nephroureterectomy; LG, low grade; HG, high grade; NR, not reported.

TABLE 3. Outcomes of series using adjuvant topical therapy for UTUC

\begin{tabular}{|c|c|c|c|c|c|c|c|}
\hline Series & $\begin{array}{c}\text { No. of } \\
\text { patients }\end{array}$ & $\begin{array}{l}\text { No. of } \\
\text { RUs }\end{array}$ & $\begin{array}{c}\mathrm{Bx}(\mathrm{G} 1 / \mathrm{G} 2 / \mathrm{G} 3) \\
(\mathrm{n})\end{array}$ & $\begin{array}{l}\text { Treatment } \\
\text { agent }\end{array}$ & $\begin{array}{l}\text { Instillation } \\
\text { route }\end{array}$ & $\begin{array}{l}\text { UT Rec, } \\
\text { n (\%) }\end{array}$ & $\begin{array}{c}\text { Mean } \\
\text { FU (mo) }\end{array}$ \\
\hline Giannarini et al. [42] & NR & 22 & NR & BCG & Antegrade & 13/22 (59) & 42 \\
\hline Rastinehad et al. [25] & NR & 89 & 89 (LG50/HG39) & BCG in $50 \mathrm{RU}$ & Antegrade & $18 / 50(36)$ & 61 \\
\hline Clark et al. [39] & 17 & 18 & $18(6 / 8 / 4)$ & BCG & Antegrade & 6/18 (33) & 11 \\
\hline Patel and Fuchs [43] & 13 & 17 & $13(8 / 5 /-)$ & BCG & Retrograde & $2 / 17(12)$ & 15 \\
\hline Cutress et al. [6] & 73 & NR & $59(34 / 19 / 6)$ & $\mathrm{MMC}$ in $18 \mathrm{RU}$ & Retrograde & $8 / 18(44)$ & 12 \\
\hline Keeley and Bagley [44] & 19 & 21 & $17(5 / 8 / 4)$ & $\mathrm{MMC}$ in $21 \mathrm{RU}$ & Retrograde & $6 / 11(54)$ & 30 \\
\hline Martinez-Pineiro et al. [26] & NR & 41 & $34(21 / 10 / 3)$ & $\mathrm{MMC}$ in $14 \mathrm{RU}$ & Ante/retrograde & $10 / 41(24)$ & 35 \\
\hline
\end{tabular}

UTUC, upper urinary tract urothelial carcinoma; RU, renal unit; Bx, biopsy; UT Rec, upper urinary tract recurrence; FU, follow-up; LG, low grade; HG, high grade; NR, not reported; BCG, Bacillus Calmette-Guerin; MMC, mitomycin C.

tient immediately and four patients during follow-up. Five patients $(20.8 \%)$ died, and four of those deaths were attributed to disease progression. The authors reported 5-year disease-specific survival rates as $79.5 \%$ and tumor-free survival rates as $68 \%$. The tumor grade and stage were predictive of disease-specific survival and recurrence-free survival.

The principal disadvantage of the percutaneous antegrade approach is the increase in morbidity compared with the ureteroscopic retrograde approach. Bleeding is a latent complication of percutaneous management owing to the vascularization of the kidney. Transfusion rates are greater than $20 \%$, while obstruction of the ureteropelvic junction from stricture, adjacent organ injury, and pleural injury are less common [24]. There is a theoretical risk of seeding resulting from tract puncture and perforations that may occur during the procedure [2]. For tract seeding, some authors have suggested placing a large sheath to decrease intrarenal pressures [23]. The reported incidence of seeding of UTUC within the percutaneous tract is extremely rare, being only $0.75 \%$ in the most experienced center [25].

Data suggest the percutaneous management of UTUC as a tolerable alternative to radical surgery in patients with low-grade, low-volume tumors. However, the elective indications for the percutaneous management of patients with high-grade tumors are unclear. This approach is being gradually abandoned owing to the development of en- hanced materials and advances in distal-tip deflection of recent ureteroscopes [2].

\section{ADJUVANT TOPICAL THERAPY}

Topical immunotherapy with Bacillus Calmette-Guerin (BCG) and chemotherapy with mitomycin $\mathrm{C}$ have been the mainstays of adjuvant topical therapy in bladder cancer. Adjuvant topical therapy has also been used after endoscopic management for UTUC in an attempt to decrease recurrences. Instillation can be performed through a percutaneous nephrostomy tube or via a retrograde ureteral catheter. The aim of therapy is continued exposure of the urothelium to the topical agent while maintaining a low pressure system that is free of infection [12]. Several agents have been used, including thiotepa, interferon, adriamycin, and mitomycin $\mathrm{C}$, but the most commonly used agent is BCG. Adjuvant topical therapy with both mitomycin C and BCG has been the most widely studied, because these agents are considered to provide the best outcomes for reducing the recurrence rates of UTUC [26].

Treatment outcomes from the current literature for adjuvant topical therapy for UTUC are summarized in Table 3. Rastinehad et al. [25] recently analyzed data gathered over 20 years with adjuvant BCG after percutaneous management of UTUC. BCG was instilled as a 6 -week course to 50 renal units, and outcomes were compared with 39 con- 
TABLE 4. Outcomes of series using adjuvant topical BCG therapy for upper urinary tract CIS

\begin{tabular}{lccccrc}
\hline \multicolumn{1}{c}{ Series } & $\begin{array}{c}\text { No. of } \\
\text { patients }\end{array}$ & No. of RUs & $\begin{array}{c}\text { Positive response, } \\
\mathrm{n}(\%)\end{array}$ & Instillation route & UT Rec, n (\%) & Follow-up (mo) \\
\hline Giannarini et al. [42] & $\mathrm{NR}$ & 42 & $\mathrm{NR}$ & Antegrade & $17 / 42(40)$ & Mean, 42 \\
Hayashida et al. [45] & 10 & 11 & $11 / 11(100)$ & Ante/retrograde & $5 / 10(50)$ & Mean, 51 \\
Miyake et al. [46] & 16 & 16 & $13 / 16(81)$ & Ante/retrograde & $3 / 16(19)$ & Mean, 30 \\
Irie et al. [47] & 9 & 13 & $13 / 13(100)$ & Retrograde & $1 / 9(11)$ & Mean, 36 \\
Thalmann et al. [48] & 22 & 25 & $22 / 25(88)$ & Antegrade & $12 / 22(55)$ & Mean, 42 \\
Okubo et al. [49] & 11 & 14 & $9 / 14(64)$ & Retrograde & $5 / 11(45)$ & Median, 49 \\
Nonomura et al. [50] & 9 & 11 & $6 / 11(82)$ & Retrograde & $2 / 9(22)$ & Mean, 20 \\
\hline
\end{tabular}

BCG, Bacillus Calmette-Guerin; CIS, carcinoma in situ; RU, renal unit; UT Rec, upper urinary tract recurrence; FU, follow-up; NR, not reported.

trol renal units. The two groups had similar underlying grade distributions. In general, there was no statistical difference in recurrence, progression, or time to recurrence between the control and treatment groups when classified by grade and stage. Cutress et al. [6] reported outcomes from 18 patients who underwent adjuvant mitomycin $\mathrm{C}$ therapy after endoscopic management. The estimated five-year UTUC recurrence-free survival was $53.8 \%$ for patients treated with adjuvant mitomycin $\mathrm{C}$ and $54.2 \%$ for those without adjuvant treatment. Even with substratification by UTUC grade, adjuvant topical treatment did not show any difference in UTUC recurrence-free survival for grade 1, grade 2 , or grade 3 UTUC.

There is no proven efficiency for the administration of adjuvant topical therapy (BCG or mitomycin C) in the management of papillary UTUC. Reports have typically been limited to small, retrospective cohort studies with limited follow-up (typically $<36$ months), mainly assessing the use of BCG and with very few assessing mitomycin C [9]. Although adjuvant topical therapy with BCG has not shown proven efficacy for papillary UTUC, several studies have reported positive outcomes for upper urinary tract carcinoma in situ (CIS). These studies collectively showed an $85 \%$ positive initial response rate and a $37 \%$ upper urinary tract recurrence rate, with a follow-up of 20 to 51 months (Table 4). The major limitation of these studies is that the diagnosis of upper urinary tract CIS was made on the basis of the presence of positive selective urine cytology and negative radiologic imaging findings rather than biopsy-proven disease. In addition, the response rates were based on restoration of normal urine cytology rather than more specific criteria, such as biopsy and ureteroscopy. Although the initial positive response rates with adjuvant BCG therapy for upper urinary tract CIS appear encouraging, the disease-specific mortality outcomes varied considerably, between $9 \%$ and $40 \%$ beyond 3 years, and have not been confirmed in longer terms [9].

The potential side effects of adjuvant BCG therapy include fever, flu-like illness, irritative voiding symptoms, septicemia, and death. It is also important to consider the risk of mitomycin $\mathrm{C}$ spillage outside the urinary tract and its tendency to generate inflammation and necrosis, espe- cially when used in a percutaneous approach [27]. Interestingly, renal function is not impaired after administration of BCG or mitomycin $\mathrm{C}$, thus preserving quality of life owing to the retained kidney [28]. In the majority of cases, complications from the instillation of chemotherapy or immunotherapy can be precluded by sustaining low intracavitary pressures during administration. Additionally, extravasation and obstruction should be systemically controlled by antegrade or retrograde radiographic opacification before the instillation of these adjuvant topical agents [29].

\section{SURVEILANCE}

Long-term endoscopic follow-up of the upper urinary tract and bladder is obligatory. As is seen in other organ-preserving management strategies, surveillance should be stringent. All patients considered candidates for endoscopic management should be counseled and be motivated enough to adhere to a regular evaluation schedule [24]. Most investigators agree that cystoscopy, urine cytology, and ureteroscopy should be performed in declining intensity as is done with bladder cancer surveillance protocols [30]. This surveillance of the upper urinary tract should be tailored to the grade and stage of the UTUC. According to the 2013 European Association of Urology Guidelines, the recommended schedule would be cystoscopy, ureteroscopy, and cytology in situ at 3 and 6 months, then every 6 months for the next 2 years, and then yearly if the patient is free from tumor recurrence. Urinary cytology and CT urography are recommended at 3 and 6 months and then yearly. This surveillance after endoscopic management for UTUC should be performed for at least 5 years. Generally, a 3-month interval follow-up protocol for the first year is the most conventional pattern [31]. However, patients should be prepared to follow the schedule and undergo repeated endoscopic surveillance.

\section{CONCLUSIONS}

UTUC is a rare disease for which relatively few patients undergo endoscopic management. The definitive purpose 
of endoscopic management is oncological control while preserving renal function and diminishing morbidity. The endoscopic management of UTUC has traditionally been utilized only for patients with imperative indications, such as renal insufficiency or a solitary functional kidney, bilateral disease, or a significant comorbidity that precluded radical surgery. More recent studies report that endoscopic treatment can be used even for elective cases (when the contralateral kidney is functional), such as a unifocal tumor, tumor size $<1 \mathrm{~cm}$, low-grade tumor (cytology or biopsies), and no evidence of an infiltrative lesion on CT urography. Patient selection is essential to successful endoscopic management. The evaluation of the overall life expectancy of a patient is a notable consideration for elective cases. Therefore, endoscopic management for UTUC has become a reasonable treatment option in highly selected patients who are expected to adhere to stringent surveillance protocols, because recurrence after endoscopic management is very common and multiple sessions may be necessary.

The current literature supports the use of adjuvant BCG therapy in patients with upper urinary tract CIS. However, the use of adjuvant topical therapy appears to accord little benefit compared with endoscopic management alone.

Definite conclusions about the outcomes of endoscopic management for UTUC cannot be made owing to the relatively low frequency of UTUC and the lack of randomized controlled trials.

\section{CONFLICTS OF INTEREST}

The authors have nothing to disclose.

\section{REFERENCES}

1. Cho DS, Hong SY, Kim YK, Kim SI, Kim SJ. Prognostic factors in transitional cell carcinoma of the upper urinary tract after radical nephroureterectomy. Korean J Urol 2011;52:310-6.

2. Roupret M, Babjuk M, Comperat E, Zigeuner R, Sylvester R, Burger M, et al. European guidelines on upper tract urothelial carcinomas: 2013 update. Eur Urol 2013;63:1059-71.

3. Lughezzani G, Sun M, Perrotte P, Shariat SF, Jeldres C, Budaus $\mathrm{L}$, et al. Gender-related differences in patients with stage I to III upper tract urothelial carcinoma: results from the Surveillance, Epidemiology, and End Results database. Urology 2010;75:321-7.

4. Margulis V, Shariat SF, Matin SF, Kamat AM, Zigeuner R, Kikuchi E, et al. Outcomes of radical nephroureterectomy: a series from the Upper Tract Urothelial Carcinoma Collaboration. Cancer 2009;115:1224-33.

5. Cho KS, Cho NH, Choi YD. Pattern of recurrence and the prognostic factors of upper urinary tract transitional cell carcinoma. Korean J Urol 2006;47:124-30.

6. Cutress ML, Stewart GD, Wells-Cole S, Phipps S, Thomas BG, Tolley DA. Long-term endoscopic management of upper tract urothelial carcinoma: 20-year single-centre experience. BJU Int 2012;110:1608-17.

7. Adamis S, Varkarakis J. Minimally invasive approach in the management of upper- urinary-tract tumours. Scand J Urol Nephrol 2011;45:381-7.

8. Daneshmand S, Quek ML, Huffman JL. Endoscopic management of upper urinary tract transitional cell carcinoma: long-term experience. Cancer 2003;98:55-60.

9. Cutress ML, Stewart GD, Zakikhani P, Phipps S, Thomas BG, Tolley DA. Ureteroscopic and percutaneous management of upper tract urothelial carcinoma (UTUC): systematic review. BJU Int 2012;110:614-28.

10. Xu AD, Ng CS, Kamat A, Grossman HB, Dinney C, Sandler CM. Significance of upper urinary tract urothelial thickening and filling defect seen on MDCT urography in patients with a history of urothelial neoplasms. AJR Am J Roentgenol 2010;195:959-65.

11. Moore K, Khastgir J, Ghei M. Endoscopic management of upper tract urothelial carcinoma. Adv Urol 2009:620604.

12. Raman JD, Scherr DS. Management of patients with upper urinary tract transitional cell carcinoma. Nat Clin Pract Urol 2007;4:432-43.

13. Bader MJ, Sroka R, Gratzke C, Seitz M, Weidlich P, Staehler M, et al. Laser therapy for upper urinary tract transitional cell carcinoma: indications and management. Eur Urol 2009;56:65-71.

14. Tawfiek ER, Bagley DH. Upper-tract transitional cell carcinoma. Urology 1997;50:321-9.

15. Cornu JN, Roupret M, Carpentier X, Geavlete B, de Medina SG, Cussenot $\mathrm{O}$, et al. Oncologic control obtained after exclusive flexible ureteroscopic management of upper urinary tract urothelial cell carcinoma. World J Urol 2010;28:151-6.

16. Chen GL, Bagley DH. Ureteroscopic surgery for upper tract transitional-cell carcinoma: complications and management. J Endourol 2001;15:399-404.

17. Soderdahl DW, Fabrizio MD, Rahman NU, Jarrett TW, Bagley DH. Endoscopic treatment of upper tract transitional cell carcinoma. Urol Oncol 2005;23:114-22.

18. Potter SR, Chow GK, Jarrett TW. Percutaneous endoscopic management of urothelial tumors of the renal pelvis. Urology 2001;58: 457-9.

19. Painter DJ, Denton K, Timoney AG, Keeley FX. Ureteroscopic management of upper-tract urothelial cancer: an exciting nephron-sparing option or an unacceptable risk? J Endourol 2008;22: 1237-9.

20. Boorjian S, Ng C, Munver R, Palese MA, Vaughan ED Jr, Sosa $\mathrm{RE}$, et al. Impact of delay to nephroureterectomy for patients undergoing ureteroscopic biopsy and laser tumor ablation of upper tract transitional cell carcinoma. Urology 2005;66:283-7.

21. Nakada SY, Clayman RV. Percutaneous electrovaporization of upper tract transitional cell carcinoma in patients with functionally solitary kidneys. Urology 1995;46:751-5.

22. Palou J, Piovesan LF, Huguet J, Salvador J, Vicente J, Villavicencio H. Percutaneous nephroscopic management of upper urinary tract transitional cell carcinoma: recurrence and long-term followup. J Urol 2004;172:66-9.

23. Roupret M, Traxer O, Tligui M, Conort P, Chartier-Kastler E, Richard F, et al. Upper urinary tract transitional cell carcinoma: recurrence rate after percutaneous endoscopic resection. Eur Urol 2007;51:709-13.

24. Argyropoulos AN, Tolley DA. Upper urinary tract transitional cell carcinoma: current treatment overview of minimally invasive approaches. BJU Int 2007;99:982-7.

25. Rastinehad AR, Ost MC, Vanderbrink BA, Greenberg KL, El-Hakim A, Marcovich R, et al. A 20-year experience with percutaneous resection of upper tract transitional carcinoma: is there an oncologic benefit with adjuvant bacillus Calmette Guérin therapy? Urology 2009;73:27-31.

26. Martinez-Pineiro JA, Garcia Matres MJ, Martinez-Pineiro L. Endourological treatment of upper tract urothelial carcinomas: analysis of a series of 59 tumors. J Urol 1996;156(2 Pt 1):377-85. 
27. Ristau BT, Tomaszewski JJ, Ost MC. Upper tract urothelial carcinoma: current treatment and outcomes. Urology 2012;79:749-56.

28. Jarrett TW, Sweetser PM, Weiss GH, Smith AD. Percutaneous management of transitional cell carcinoma of the renal collecting system: 9-year experience. J Urol 1995;154:1629-35.

29. Audenet F, Traxer O, Bensalah K, Roupret M. Upper urinary tract instillations in the treatment of urothelial carcinomas: a review of technical constraints and outcomes. World J Urol 2013;31: 45-52.

30. Thompson RH, Krambeck AE, Lohse CM, Elliott DS, Patterson DE, Blute ML. Elective endoscopic management of transitional cell carcinoma first diagnosed in the upper urinary tract. BJU Int 2008;102:1107-10.

31. Sowter SJ, Ilie CP, Efthimiou I, Tolley DA. Endourologic management of patients with upper-tract transitional-cell carcinoma: long-term follow-up in a single center. J Endourol 2007;21: 1005-9.

32. Fajkovic H, Klatte T, Nagele U, Dunzinger M, Zigeuner R, Hubner $\mathrm{W}$, et al. Results and outcomes after endoscopic treatment of upper urinary tract carcinoma: the Austrian experience. World J Urol 2013;31:37-44.

33. Pak RW, Moskowitz EJ, Bagley DH. What is the cost of maintaining a kidney in upper-tract transitional-cell carcinoma? An objective analysis of cost and survival. J Endourol 2009;23:341-6.

34. Lucas SM, Svatek RS, Olgin G, Arriaga Y, Kabbani W, Sagalowsky AI, et al. Conservative management in selected patients with upper tract urothelial carcinoma compares favourably with early radical surgery. BJU Int 2008;102:172-6.

35. Johnson GB, Fraiman M, Grasso M. Broadening experience with the retrograde endoscopic management of upper urinary tract urothelial malignancies. BJU Int 2005;95 Suppl 2:110-3.

36. Deligne E, Colombel M, Badet L, Taniere P, Rouviere O, Dubernard JM, et al. Conservative management of upper urinary tract tumors. Eur Urol 2002;42:43-8.

37. Keeley FX Jr, Bibbo M, Bagley DH. Ureteroscopic treatment and surveillance of upper urinary tract transitional cell carcinoma. J Urol 1997;157:1560-5.

38. Goel MC, Mahendra V, Roberts JG. Percutaneous management of renal pelvic urothelial tumors: long-term followup. J Urol 2003;169:925-9.

39. Clark PE, Streem SB, Geisinger MA. 13-year experience with percutaneous management of upper tract transitional cell carci- noma. J Urol 1999;161:772-5.

40. Patel A, Soonawalla P, Shepherd SF, Dearnaley DP, Kellett MJ, Woodhouse CR. Long-term outcome after percutaneous treatment of transitional cell carcinoma of the renal pelvis. J Urol 1996;155:868-74.

41. Fuglsig S, Krarup T. Percutaneous nephroscopic resection of renal pelvic tumors. Scand J Urol Nephrol Suppl 1995;172:15-7.

42. Giannarini G, Kessler TM, Birkhauser FD, Thalmann GN, Studer UE. Antegrade perfusion with bacillus Calmette-Guérin in patients with non-muscle-invasive urothelial carcinoma of the upper urinary tract: who may benefit? Eur Urol 2011;60:955-60.

43. Patel A, Fuchs GJ. New techniques for the administration of topical adjuvant therapy after endoscopic ablation of upper urinary tract transitional cell carcinoma. J Urol 1998;159:71-5.

44. Keeley FX Jr, Bagley DH. Adjuvant mitomycin C following endoscopic treatment of upper tract transitional cell carcinoma. J Urol 1997;158:2074-7.

45. Hayashida Y, Nomata K, Noguchi M, Eguchi J, Koga S, Yamashita $\mathrm{S}$, et al. Long-term effects of bacille Calmette-Guérin perfusion therapy for treatment of transitional cell carcinoma in situ of upper urinary tract. Urology 2004;63:1084-8.

46. Miyake H, Eto H, Hara S, Okada H, Kamidono S, Hara I. Clinical outcome of bacillus Calmette-Guérin perfusion therapy for carcinoma in situ of the upper urinary tract. Int J Urol 2002;9:677-80.

47. Irie A, Iwamura M, Kadowaki K, Ohkawa A, Uchida T, Baba S. Intravesical instillation of bacille Calmette-Guérin for carcinoma in situ of the urothelium involving the upper urinary tract using vesicoureteral reflux created by a double-pigtail catheter. Urology 2002;59:53-7.

48. Thalmann GN, Markwalder R, Walter B, Studer UE. Long-term experience with bacillus Calmette-Guerin therapy of upper urinary tract transitional cell carcinoma in patients not eligible for surgery. J Urol 2002;168(4 Pt 1):1381-5.

49. Okubo K, Ichioka K, Terada N, Matsuta Y, Yoshimura K, Arai Y. Intrarenal bacillus Calmette-Guérin therapy for carcinoma in situ of the upper urinary tract: long-term follow-up and natural course in cases of failure. BJU Int 2001;88:343-7.

50. Nonomura N, Ono Y, Nozawa M, Fukui T, Harada Y, Nishimura $\mathrm{K}$, et al. Bacillus Calmette-Guérin perfusion therapy for the treatment of transitional cell carcinoma in situ of the upper urinary tract. Eur Urol 2000;38:701-4. 